\title{
ХРОНОТОП СТРАННИЧЕСТВА В РУССКОЙ ЖИВОПИСИ ВТОРОЙ ПОЛОВИНЫ ХІХ ВЕКА
}

\section{CHRONOTOPE OF WANDERINGS IN RUSSIAN PAINTING SECOND HALF OF THE XIX CENTURY}

\section{Balonova}

Summary: The goal of this article consists in examination of the archetype and the chronotype of wandering in Russian pictorial art of the second half of the XIX century is regarded. The special attention is given to the works of Peredvizhniki (the Itinerants). Based on historical, comparative, typological and semiotic research methods the author explores the formal and content features of the chronotype of wandering. It is concluded that this chronotype becomes a frame thanks to which the artists and viewers search for their self-identity.

Keywords: chronotype of wandering, Russian pictorial art of the second half of the XIX century, Peredvizhniki (the Itinerants), motif of the road, archetype, identity.
$\Phi$ еномен странничества получил широкое распространение в отечественной культуре в силу многих причин, среди которых «...и географические (необъятные просторы отечества), и геокультурные (расположение на стыке Востока и Запада), и геополитические (необходимость осваивать и отстаивать территории в сложных климатических условиях и в противостоянии с внешними конкурентами), и религиозные (путешествия к святым местам), и социальные (поиски места приложения своих сил, “лучшей доли")...» $[2$, c. 33].

Интерес к теме и мотиву странничества в произведениях русского искусства ярко выражен в XIX веке, особенно в его второй половине, когда актуализируется рефлексивное начало российской культуры. Наиболее акцентировано эта тенденция проявилась в живописи указанного периода в творчестве членов Товарищества передвижных художественных выставок (ТПХВ), а также художников, близких им по духу. Сами передвижные экспозиции были элементом страннической культуры. Странничество в Российской империи, по справедливому наблюдению И.П. Смирнова, «отнюдь не исчерпывалось одной эстетической сферой... превращалось в жизненный жест (уход Толстого из Ясной Поляны, инсценировка бездомности Набоковым на склоне лет); обусловливало инновативно-организационную практику деятелей искусства (“Товарищество передвижных выставок", турне, затеянные футуристами)...» [4, с. 242].
Балонова Марина Григорьевна

к.филол.н., доцент, Российская академия государственной службы и народного хозяйства при Президенте Российской Федерации, г. Москва balonova76@mail.ru

Аннотация: Целью статьи является исследование архетипа и хронотопа странничества в русской живописи второй половины XIX века, при этом особое внимание уделяется творчеству представителей Товарищества передвижных художественных выставок. Формально-содержательные элементы хронотопа странничества в живописных произведениях анализируются на основе исторического, сравнительно-типологического и семиотического методов. Делается вывод о том, что хронотоп странничества, воплощенный в пейзажах представителей ТПХВ, становится фреймом, посредством которого как художник, так и зритель осуществляют поиск самоидентичности и идентичности своего отечества.

Ключевые слова: хронотоп странничества, русская живопись второй половины XIX века, передвижники, мотив дороги, архетип, идентичность.

Феномен странничества привлекает внимание отечественных исследователей последних десятилетий, что неудивительно, так как странничество аккумулирует в себе многие сущностные черты русского народа и является во многом специфическим российским явлением. «В русской культуре феномен странничества, - пишет Д.Б. Дорофеев, - представлен не так разнообразно, как в западной, но именно поэтому его значение более велико: оно не распыляется в множестве форм, но являет собой целостный тип, крайне существенный для русского сознания...» [3, с. 71]. В работах на эту тему ученые преимущественно обращаются к анализу странничества либо в широком философско-культурологическом, либо в литературоведческом аспектах; рассматривая же ее воплощение в изобразительном искусстве, прежде всего ориентируются на произведения, в которых мотив странничества представлен эксплицитно - через образы скитальца, богомольца, странствующего певца, сказителя, нищего и т.д.

Эти образы становятся сюжетообразующими в живописи многих отечественных художников второй половины XIX в. Это творения В.Г. Перова (работы под названием «Странник» 1859, 1869 и 1870 гг.; «Чаепитие в Мытищах», 1862; «Прием странника», 1874; «Странница в поле», 1879; «Блаженный», 1879), М.Н. Крамского («Созерцатель», 1876), Н.А. Кошелева («Странница, 1876), И.М. Прянишникова («Калики перехожие», 1870 (Рисунок 1)), Н.А. Ярошенко («Слепые калики под Киевом», 1879), В.М. 
Васнецова («Нищие певцы», 1873), В.Д. Поленова («Сказитель былин Никита Богданов», 1876), этюды и наброски В.И. Сурикова и И.Е. Репина и другие. К ним примыкают работы, в которых в качестве странника выступает воин, защитник Отечества («Богатыри», 1898, «Витязь на распутье», 1882, В.М. Васнецова) и т. п. Кроме фигуры человека (часто с сумой, посохом, в дорожной одежде), являющегося инвариантом странника, в этих работах также присутствуют формально-содержательные элементы и атрибуты хронотопа странничества, но они лишь задают сюжетный фон картины: основным действующим лицом, несущим смысловую нагрузку странничества, остается человек.

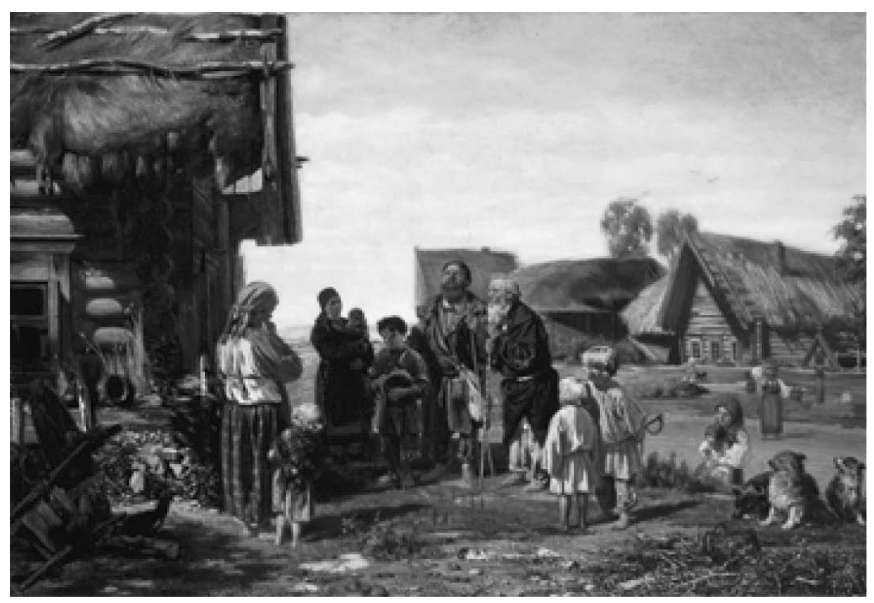

Рис. 1. И.М. Прянишников. Калики перехожие. 1870. Х., м.

Государственная Третьяковская галерея, Москва

Однако мотив странничества в отечественной живописи и графике нуждается также в рассмотрении не столь буквальном, и, следовательно, избирательном. Данное явление, на наш взгляд, представляет собой архетип, который в произведениях изобразительного искусства реализуется чаще всего в соответствующем хронотопе. Во многом благодаря определенному пространству-времени, ставшему одной из парадигм отечественной культуры, в них воплощается идея поиска человеком самого себя и идентичности России в целом. Актуальность анализа этого хронотопа состоит в том, что он позволяет глубже понять особенности формально-содержательной структуры произведений русского изобразительного искусства, а также выйти на исследование проблем идентичности русской культуры с точки зрения ее отражения в живописи.

Многие отечественные пейзажи рассматриваемого периода, на которых нет изображения странствующего человека или его фигура имеет стаффажный характер, пропитаны духом странничества часто даже в большей степени, чем вышеперечисленные. Это целый ряд произведений И.И. Левитана, А.И. Куинджи, творения И.И. Шишкина («Рожь», 1878; «Кама близ Елабуги», 1895), Ф.А. Васильева («Оттепель», 1871; «Перед грозой», 1868-
1869 (Рисунок 2)), Г.Г. Мясоедова («Дорога во ржи», 1881; «Зреющие нивы», 1892), М.К. Клодта («Большая дорога осенью», 1863; «Лесная даль в полдень», 1876) и других художников.

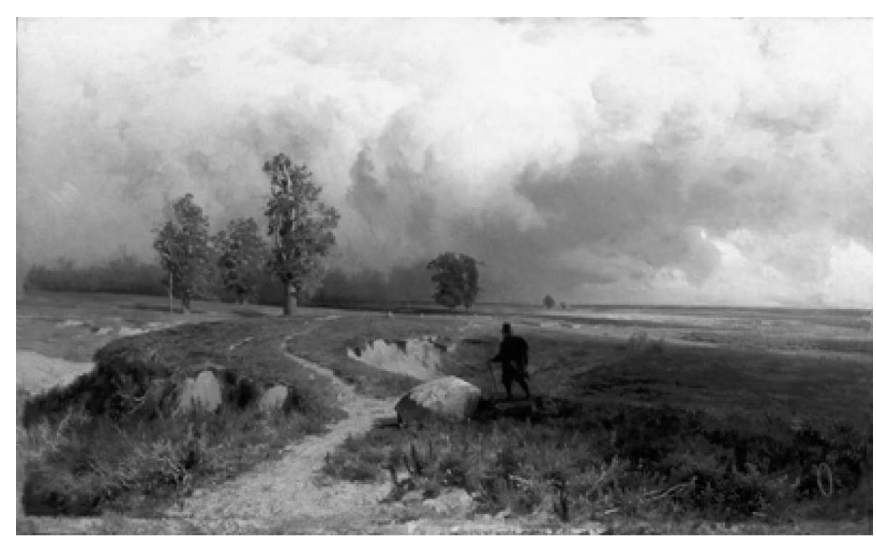

Рис. 2. Ф.А. Васильев. Перед грозой. 1868-1869. Х., м. Нижегородский государственный художественный музей

Основными формально-содержательными скрепами хронотопа странничества в живописи этих авторов являются: дорога, река, тропинка, выступающие на холстах в качестве центрального образа; отсутствие прямых направлений; далекий горизонт; церковь, монастырь и другие приметы христианской и богомольческой культуры (голубец, кресты, погост). Важную роль в создании пространства странничества играет небо, которому, как правило, отводится значительная или бо̀льшая часть холста как символу вечности и восхождения к Царству Божьему. В пейзажах с данным хронотопом преобладают горизонтали (и здесь уместно вспомнить «бесконечную равнину» О. Шпенглера, которую он считал прасимволом русской культуры).

На этих холстах пространство, как правило, открыто во всех направлениях; первый план, лишенный какихто преград, приглашает зрителя в долгое путешествие. Четкое разделение на планы, кулисное построение композиции, присущие пейзажам классицизма, им чуждо. Дорога (вариант - река) обладает в пейзажах передвижников семантикой, актуальной именно для живописи второй половины XIX века, - семантикой духовного поиска. Это становится очевидным, если сравнивать изображение дороги в творчестве мастеров ТПХВ с этим же мотивом и в работах отечественных художников Серебряного века (А.Н. Бенуа, Е.Е. Лансере, К.А. Сомова, В.Э. Борисова-Мусатова и др.).

Передвижникам интересен эпичный, естественный (природный) ландшафт, не структурированный человеком. Дорога в их произведениях - извилистая, уводящая в неопределенном направлении - придает пейзажам повествовательный характер, предлагает бесконечный временной и пространственный вектор движения, при- 
зывает зрителя к неторопливым размышлениям о себе, мире и о своем месте в нем. Для работ же мастеров Серебряного века преимущественно свойственны заданные направления, замкнутые и обустроенные человеком камерные природные пространства, прямые дороги и дорожки. Мирискусники чаще всего предпочитают культурные (искусственные) ландшафты, организованные по законам театральной сцены. Функции мотива дороги в произведениях представителей «Мира искусства» прежде всего композиционные и декоративные, тогда как в творчестве передвижников на первый план выступает его смыслообразующая функция.

Коннотации странничества в пейзажах передвижников воплощаются также благодаря особым временным характеристикам произведений. Повествовательность, заданная берущей начало из ниоткуда и вдаль уходящей дорогой, делает время в этих произведениях разомкнутым в обоих направлениях. Леса и поля, реки, луга и озера, культовые архитектурные сооружения, фигурки людей, видимые в основном издали, - эти образы не имеют конкретной хронологической привязки.

Таким образом, хронотоп подобных произведений открыт и с точки зрения пространства, и с точки зрения времени. Вследствие этого создается своеобразный фрейм их рецепции, а именно: формированию ощущения бесконечного путешествия без какой-либо рационально поставленной цели способствует зритель, наполняя пейзаж своими воспоминаниями и эмоционально окрашенными ассоциациями. В процессе восприятия этих произведений на уровне подтекста в работу включаются пласты исторической, коллективной и индивидуальной памяти.

Историческую память мы определяем в качестве объективного (или признаваемого таковым на определенном этапе) исторического знания, по возможности очищенного от субъективных оценок. На уровне исторической памяти на актуализацию семантики странничества в пейзажах передвижников работают знания зрителей об исторических событиях, происходивших на обширной российской территории (набеги кочевников; великие сражения; вынужденные переселения по воле правителя или в поисках лучшей доли; покорение новых земель по типу завоевания Сибири Ермаком Тимофеевичем и пр.)

Коллективная память - «память о событиях, фактах, по-разному окрашенная в воспоминаниях представителей определенных групп; закрепленная в традиции, сознании и подсознании группы; коннотации на факты, события; общие для какой-либо группы ценностные (этические и эстетические) суждения, способствующие формированию социальной идентичности» [1, с. 40]. Пласт коллективной памяти позволяет наполнить лишенные событийности пейзажи повествовательностью и ассоциациями со странничеством как духовным явлением, связанным с поисками идентичности. Открытый хронотоп пейзажей передвижников на этом уровне рецепции заполняется разделяемыми народом представлениями о добре и зле, судьбе, предназначении человека и о его жизненном пути, подчерпнутыми из фольклора, эпоса, православной культуры, русского классического искусства и т. п., - всего того, что формирует и воплощает нравственный и духовный код нации.

Помимо исторической и коллективной памяти, на обогащение восприятия пейзажей с мотивом странничества работает и индивидуальная память человека, а именно те ее аспекты, что связаны с родной русской природой, домом, детством, семьей.

Например, «Владимирка» И.И. Левитана, 1892 (Рисунок 3), наполняется для зрителя подлинным смыслом лишь тогда, когда он осведомлен о том историческом факте, что по этому тракту проходил отрезок пути в Сибирь заключенных-каторжан. Именно это знание позволяет воспринимать шедевр Левитана как «исторический пейзаж» (выражение художника М.В. Нестерова). Кроме того, рецепция этого холста значительно обеднена в случае, если человек не знаком с классическими произведениями отечественного искусства и заложенным в них культурным кодом, а также с героями и сюжетами русских сказок и былин, православной богомольческой культурой и ее историей; не имеет опыта эмоциональной сопричастности русской природе. Именно за счет хронотопа, обогащенного этими и подобными коннотациями, в пейзажах передвижников «аккумулируются размышления о прошлом и неопределенном будущем России» $[2$, с. 34].

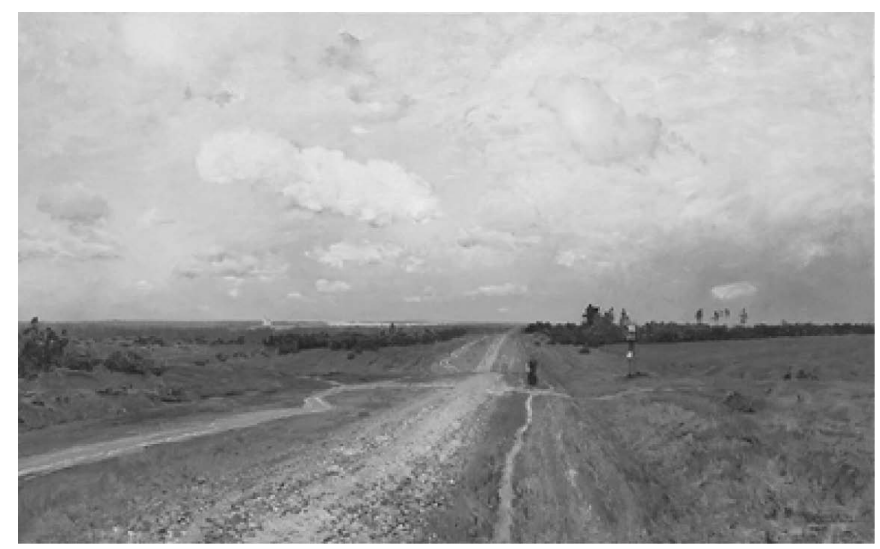

Рис. 3. И.И. Левитан. Владимирка. 1892. Х., м. Государственная Третьяковская галерея, Москва

Итак, живописные произведения художников-передвижников, в которых воплощен мотив странничества, можно уверенно подразделить на две группы. В работах первой группы тема странничества представлена 
эксплицитно за счет их центрального образа - богомольца, странствующего певца, нищего, калики перехожего и т. д. Произведения второй группы представляют собой пейзажи, в которых феномен странничества отражен имплицитно, на уровне подтекста. Архетип странничества передается в данных пейзажах за счет определенного хронотопа, разомкнутого как в аспекте пространственных, так и временных характеристик. Этот хронотоп с точки зрения смыслообразующей представляет собой фрейм восприятия, который обогащается за счет исторической, коллективной и инди- видуальной памяти зрителя, погруженного в русскую природу, историю и культуру. Именно его, зрителя, эмоциональные коннотации делают данные пейзажи повествовательными, заставляют размышлять о прошлом, настоящем и будущем как самого себя, так и своего отечества. Так живописные пейзажи членов ТПХВ в образной форме представляют собой поиск ответа на вопросы об идентичности России, о месте человека на ее бескрайних просторах и о его роли в ее многовековой истории, становясь своеобразным «Камо грядеши» на русской почве.

\section{ЛИТЕРАТУРА}

1. Балонова М.Г. Memory studies: аспекты применения в искусствоведении // Вестник Нижегородского института управления: электронное научное издание. — 2016. — № 3. — C. 39-45. — URL: http://old.niu.ranepa.ru/nauka/?page_id=7158 (дата обращения: 02.05.2020)

2. Балонова М.Г. Странничество в русской живописи второй половины XIX века (к постановке проблемы) // Вестник Нижегородского института управления: электронное научное издание. — 2020. — № 1. — C. 32-35. — URL: http://services.niu.ranepa.ru/nauka/?page_id=8472 (дата 06ращения: 02.05.2020)

3. Дорофеев Д.Б. Феномен странничества в западноевропейской и русской культурах // Вестник культурологии. — 2010. — № 1. — С. 63-87.

4. Смирнов И.П. Генезис. Философские очерки по социокультурной начинательности. - СПб.: Алетейя, 2006. — 288 с.

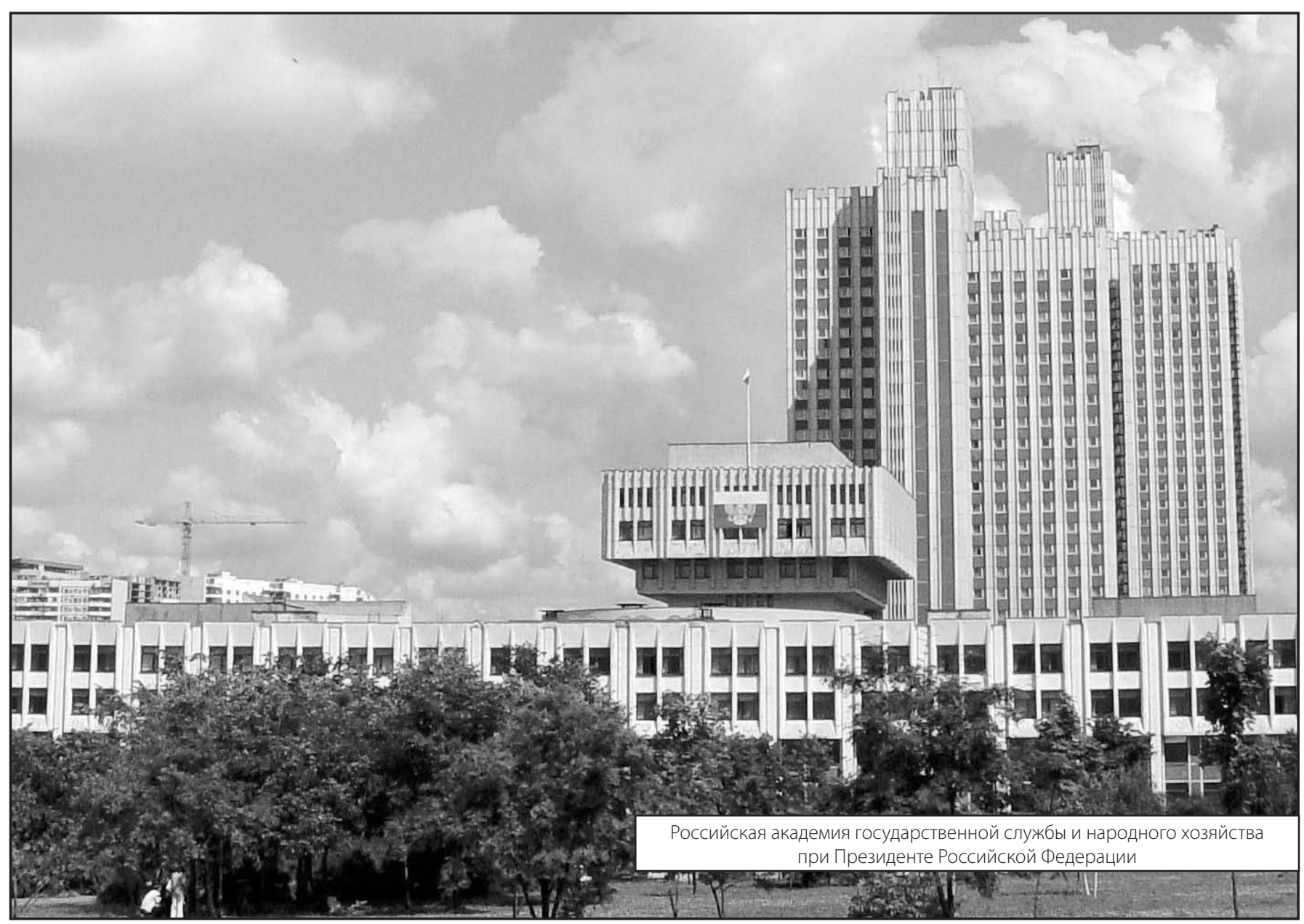

